\section{Introduction and Perspective of the Colloquium}

\author{
Robert J. Dufault'
}

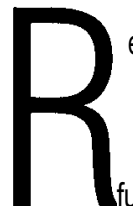

esearch developments on many fronts and by many institutions hold promise for considerable improvements in crop establishment in the near future, with ensuing economic advantages. Economic pressures have governed the changes necessary for successful transplanting techniques. It is long past the time when a grower can plant seed..

One for the rook, one for the crow,

One to rot and one to grow ..... (Salter,1985)

Excess direct-seeding and thinning of many new hybrid varieties is cost-prohibitive. Salter (1982) defined the advantages of transplanting containerized plants rather than direct-seeding as follows:

1) More-reliable establishment of the required population and better control of spacing.

2) More-predictable timing of production.

3) Greater potential for early crops.

4) A more-intensive rotation per unit area during the growing season.

5) Higher yields from some crops.

6) Greater uniformity of some crops.

7) Greater potential for success with marginal crops.

8) More-efficient use of expensive seed.

To offset the increased cost of transplants, smaller containers tend to be used because they save greenhouse bench space and time to produce a transplant crop. However, as the container decreases in size, the newly planted seedling is more susceptible to extremes of seedbed stresses, such as damage from pests and adverse soil temperature, moisture, oxygen, structure, nutrients, and salts during transplanting. Small seedlings, however, require more time to reach maturity than large transplants.
Research has accumulated within the past few years that provides insights into the significance of new techniques for transplant propagation, handling, and storage prior to transplanting. New, and improved, techniques have been researched for the manipulation of transplant growth during the greenhouse production phase-not only to improve plant establishment and reduce transplant shock soon after transplanting, but to enhance long-term field growth and yield performance. Some of the new methodologies manipulate nutrition, light quality and quantity, temperature, and mechanical conditioning. Some of these techniques are so new that they are not used commercially at present nor have been published in the literature. Some of these techniques may not be readily adapted commercially because the largescale mechanics of imposing these techniques have not been developed. Eventual commercial adaptation of these techniques may provide new ways of propagating higher-quality seedlings predisposed to tolerate field stresses better and to enhance earliness, higher total yield, and improved quality in comparison with methodologies in use currently.

The objectives of this colloquium were to:

1) Examine current state-of-the-art commercial production systems inselected locations in the United States, Australia, and Japan;

2) review the latest academic research findings in transplant propagation techniquesand the perceived constraintsand limitations to their commercial adaptation;

3) solicit commercial critiques on the practicality, feasibility, and economics of research innovations; and

4) discuss current engineering innovations for the automation of transplant production.

\section{Literature Cited}

Salter, P. J. 1982. Advantages and disadvantages of module-raised vegetable plants. Scientia Hort. $33: 76-81$

Salter, PJ. 1985. Crop establishment: Recent researchand trends in commercial practice. Scientia Hort 36:32-47.
Clemson University, Coastal Research and Education Center, 2865 Savannah Highway, Charleston, SC 29414.

'Associate Professor. 